\title{
VARIABILIDADE ISOENZIMÁTICA ENTRE LINHAGENS DE AMENDOIM RESISTENTES À SECA
}

\author{
ISOENZIMATIC VARIABILITY BETWEEN PEANUT \\ LINES RESISTANT TO DROUGHT
}

\author{
Roseane Cavalcanti dos Santos $^{1}$ José de Alencar Nunes Moreira $^{1}$ \\ Jair Moura Duarte ${ }^{2}$
}

\section{RESUMO}

\begin{abstract}
O uso da técnica de eletroforese para separar múltiplas formas moleculares de enzimas tem sido bastante explorada na área biológica, cujas diferenças detectadas nos tecidos podem ser eficientemente usadas para diferenciação de cultivares em qualquer fase de seu desenvolvimento fenológico. Nesse trabalho, procedeu-se ao estudo da variabilidade isoenzimática em seis linhagens de amendoim resistentes à seca, com o objetivo de se verificar as possíveis relações da variação encontrada na base desses descritores com essa aptidão no amendoim. Estudaram-se foliolos da parte apical com 5 dias após a germinação, utilizando-se a técnica de eletroforese em gel de poliacrilamida (7\%) sistema horizontal e contínuo de tampão. Os sistemas estudados foram fosfatase ácida (ACP), malato desidrogenase (MDH), leucina aminopeptidase (LAP), peroxidase (PO), e esterase (EST). A caracterização fenotípica dos genótipos permitiu a separação de quatro grupos para ACP, três para LAP, dois para MDH e seis para PO e EST. A partir da análise dos componentes principais dos grupos obtidos, observou-se que a cultivar IAC Tupã (sensível à seca) foi separada das demais, especialmente da cultivar resistente Senegal 55437.
\end{abstract}

Palavras-chave: Arachis hypogaea, eletroforese, enzima, componentes principais.

\section{SUMMARY}

The use of electrophoretic techniques to separate multiple molecular forms of enzymes has been used in the biological science, where differences in isozymes among tissues can be used efficiently on cultivar differentiation during any life cycle phase. In this paper, the variability of six drought resistant peanut lines was studied by isozymes analysis aiming to verify the possible relations between enzymatic descriptors and drought resistance character. Leaflets were analyzed by horizontal poliacrylamide gel electrophoresis technique and buffer continuos systems for the following systems: acid phosphatase $(A C P)$, malate dehydrogenase $(M D H)$, leucine aminopeptidase $(L A P)$, peroxidase $(P O X)$ and esterase (EST). The phenotypic characterization of the genotypes allowed four group separations to ACP, three to LAP, two to MDH, and six to POX and EST. The IAC Tupã cultivar (drought sensitive) was differentiated to the others genotypes, specially as to Senegal 55437 cultivar (drought resistant) by principal components analysis.

Key words: Arachis hypogaea, electrophoresis, enzyme, principals components.

\section{INTRODUÇÃO}

As plantas diferem largamente quanto à habilidade de tolerar o estresse hídrico. Nas sensíveis, os processos fisiológicos são adversamente afetados devido à redução na hidratação dos tecidos; nas tolerantes, suas propriedades morfológicas e metabólicas as capacitam para manter um alto grau de hidratação dos tecidos mesmo sob limitado suprimento hídrico. Tais plantas podem sobreviver longos períodos de baixa hidratação tissular.

A detecção da variabilidade das plantas para esse caráter em nível das isoenzimas tem sido de grande utilidade para apoiar o melhoramento genético quanto à identificação de cultivares, à análise da estrutura genética de populações e ao estabelecimento de marcadores para as características de natureza quantitativa.

\footnotetext{
1 Engenheiro Agrônomo, MSc, Pesquisador EMBRAPA - Algodão, CP 174, 58107-720, Campina Grande, PB. Autor para correspondência: roseane@ cenargem.embrapa.br

${ }^{2}$ Estudante de Agronomia da Universidade Federal da Paraíba, Estagiário do Projeto Amendoim, Embrapa - Algodão. Recebido para publicação em 13.10.98. Aprovado em 04.08.99
} 


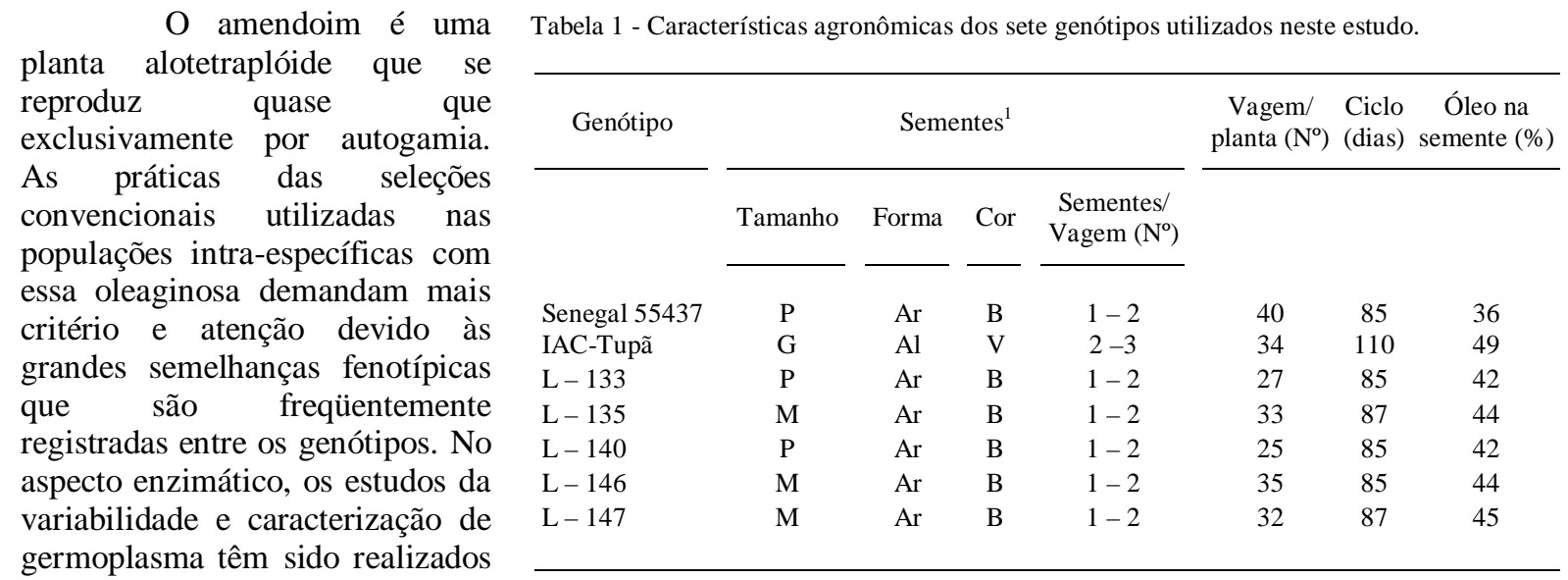
por diversos autores (CHERRY \& ORY, 1973; GRIESHAMMER \& WINNE， 1990; GALGARO \&

${ }^{1} \mathrm{P}=$ pequena, $\mathrm{M}=$ média, $\mathrm{G}=$ grande $; \mathrm{Ar}=$ arredondada $; \mathrm{Al}=$ alongada $; \mathrm{V}=$ vermelha, $\mathrm{B}=$ bege

LOPES, 1994). No entanto, são pouco informativos no que tange ao esclarecimento das relações entre a variação em nível das isoenzimas e características de importância para o melhoramento genético, como é o caso, por exemplo, da tolerância à seca, cujo caráter é de grande expressão no amendoim.

No presente trabalho, estudou-se a variabilidade isoenzimática em linhagens com resistência à seca, com objetivo de verificar as possíveis relações da variação encontrada na base desses descritores com tal aptidão no amendoim cultivado.

\section{MATERIAL E MÉTODOS}

Foram estudados sete linhagens, dentre as quais seis com característica de resistência à seca, procedentes do International Crops Research Institute For The Semi - Arid Tropics (ICRISAT, Índia) e uma do Instituto Agronômico de Campinas (IAC). Entre o grupo de linhagens com resistência à seca, encontra-se a cultivar Senegal 55 437, altamente precoce e de grande adaptação ao cultivo em ambientes semi-áridos (BOOTE et al. 1982) e mais cinco descendentes dessa, originados de um cruzamento piramidal envolvendo oito parentais, todos com características de resistência à seca. A outra cultivar foi representada pela IAC Tupã, sensível às condições de estresse hídrico e, como tal, foi utilizada para termos de comparação com as demais linhagens. Uma síntese das características agronômicas dos genótipos encontra-se na tabela 1 .

Três sementes de cada linhagem foram cultivadas em vasos contendo areia lavada na casa de vegetação da Embrapa -Algodão, em Campina Grande, PB, perfazendo um total de 35 vasos (cinco para cada linhagem). A análise eletroforética foi realizada utilizando-se os folíolos situados na parte apical das plântulas, quando eles se encontravam com cinco dias após a germinação. Para cada amostra, triturou-se $1 \mathrm{~g}$ de folíolos em $4 \mathrm{~m} \ell$ de $\mathrm{NaCl}$ $0,15 \mathrm{M} \mathrm{pH} \mathrm{7,1,} \mathrm{conforme} \mathrm{metodologia} \mathrm{descrita} \mathrm{por}$ SANTOS (1989). Após a homogeneização, o material foi centrifugado por $10 \mathrm{~min}$, a $7.000 \mathrm{rpm}$; em seguida, as amostras foram mantidas sob refrigeração, sendo os sobrenadantes utilizados nas análises eletroforéticas.

O meio suporte utilizado foi o gel de poliacrilamida a 7\%, sistema contínuo e horizontal (DUARTE, 1997). As migrações eletroforéticas foram mantidas a $4^{\circ} \mathrm{C}$ durante $4 \mathrm{~h}$, com uma diferença de potencial de 8,8 volts/cm de gel. Os sistemas estudados foram: fosfatase ácida, malato desidrogenase, leucina amidopeptidase, peroxidase e esterase segundo metodologia descrita por ALFENAS et al. (1991).

A análise dos dados para cada sistema foi realizada comparativamente entre as linhagens estudadas, utilizando-se zimogramas e obedecendose aos procedimentos descritos em QUIROS (1980). $\mathrm{Na}$ análise estatística dos resultados, cada banda foi tomada como variável qualitativa e identificada como 1, quando presente, e 0 no caso de ausente. A classificação das cultivares foi realizada pelas análises das componentes principais e de conglomerados (MOREIRA et al. 1994); a primeira foi procedida a partir dos dados com a presença (1) e ausência (0) de banda, referentes a cada sistema nas cultivares estudadas. No caso da análise de conglomerados, adotou-se o coeficiente de emparelhamento simples, o qual reflete o número de bandas idênticas que duas cultivares compartilham entre si.

A matriz de similaridade foi constituída pelos valores desses coeficientes, calculados para cada par de cultivares em todas as combinações possíveis. A partir dessa, aplicou-se o método de conglomeração do ligamento simples, com o qual foi 
possível agrupar as diversas linhagens. Os dados assim gerados foram usados para se construir o dendrograma com o qual foi possível estabelecer-se as relações entre os materiais em estudo.

\section{RESULTADOS E DISCUSSÃO}

O perfil enzimático da fosfatase ácida (ACP) forneceu quatro padrões compostos de seis diferentes regiões que exibiram mais diferenças na intensidade de coloração do que no número de bandas (Figura 1- ACP). Entre os quatro grupos fenotípicos detectados, apenas o D, composto pela linhagem L 146 AM, não apresentou a região ACP1 entre os demais materiais estudados.

De acordo com o padrão fenotípico obtido com essa enzima, observa-se que a cultivar sensível IAC Tupã enquadrou-se no mesmo grupo da resistente Senegal 55 437. Como são bastante diferentes entre si no aspecto morfo-fisiológico (Tabela 1), percebe-se que, apenas com esse sistema, não é possível estabelecer qualquer relação entre essas duas cultivares para o caráter em apreço nas

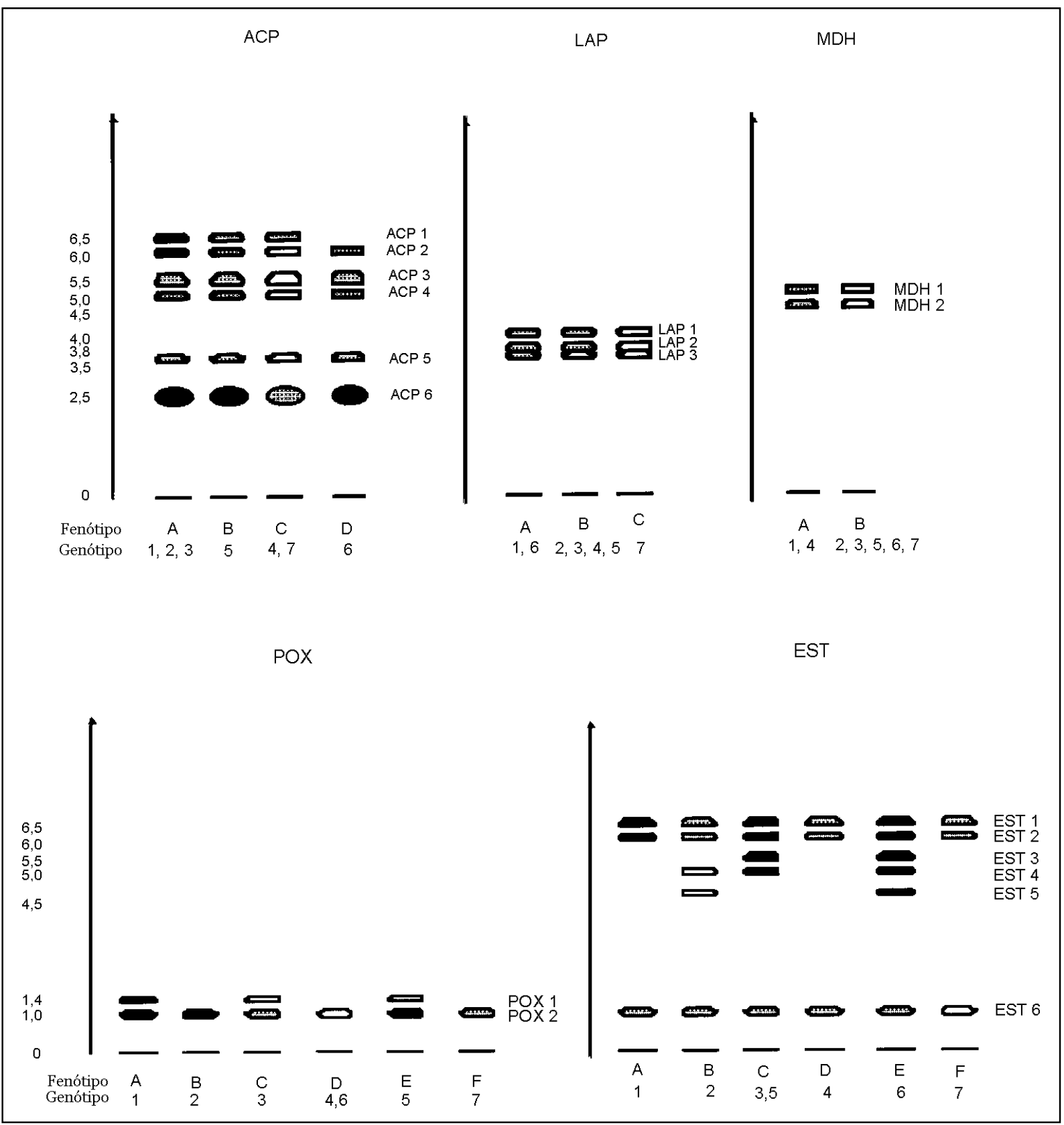

Figura 1 - Padrões fenotípicos de ACP, LAP, MDH, POX e EST em folíolos. Genótipos: 1 - IAC Tupã, 2 - Senegal 55 437, 3 - L 133 AM, 4 - L 135 AM, 5 - L 140 AM, 6 - L 146 AM, 7 - L 147 AM. Intensidade de coloração: forte - $\mathbf{\square}$, normal - $\square$, fraca - $\square$

Ciência Rural, v. 30, n. 2, 2000. 
condições fenológicas do presente estudo. Contudo, como essa enzima responde a variações ambientais e tem especificidade tissular, é possível que se obtenha resultados diferentes através da indução de mudanças ambientais na população, como estresse hídrico, por exemplo, ou através da análise ontogenética de outros tecidos da planta.

Segundo HALL (1969), a ACP juntamente com a EST e a POX, é uma enzima muito utilizada para detecção de marcadores, porque costuma apresentar polimorfismo. $\mathrm{O}$ autor ressalta, contudo, que elas atuam sobre vários substratos e assim, dependendo do protocolo de revelação, podem apresentar padrões ou atividades diferentes de tecido para tecido. No presente estudo, o corante e substrato utilizados foram Fast Garnet GBC Salt e $\alpha$ Naftil fosfato ácido de sódio, respectivamente.

Para a leucina aminopeptidase (LAP), três padrões fenotípicos foram obtidos com esse sistema, todos apresentando o mesmo número de regiões enzimáticas (Figura 1- LAP). O grupo B agrupou quatro genótipos, entre eles a cultivar Senegal 55437 e as linhagens L 133 e L 140, que são bastante similares entre si, não apenas no aspecto agronômico, mas também no fisiológico. No perfil de Malato desidrogenase (MDH), constituído por duas regiões, dois grupos foram estabelecidos e, mais uma vez, os três genótipos acima referidos estiveram presentes (Figura 1- MDH). As regiões, contudo, apresentaram pouca variação, devendo estar relacionada possivelmente à idade e ao tipo de tecido estudado, uma vez que, segundo LONGO \& SCANDALIOS (1963) e NEWTON \& SCHAWARTZ (1980), as formas citoplasmáticas e mitocondriais da MDH são mais ativas nas raízes, gemas, endosperma, hipocótilo, folhas adultas e pólen.

$\mathrm{O}$ padrão da peroxidase (POX) apresentou apenas duas regiões. A intensidade de coloração em que a mesma foi flagrada, contudo, permitiu a obtenção de seis padrões, o que proporciou, praticamente, um fenótipo para cada linhagem. A exceção foi $o$ grupo $D$, que compreendeu dois materiais, L 135 e L 146 (Figura 1- POX). A região responsável pela diferenciação foi a POX1 que foi observada em apenas três linhagens desse estudo, com gradação de tonalidade indo desde a fraca até a fortemente corada.

A alta capacidade dessa enzima para discriminação de cultivares tem sido relatada por diversos autores. Sua detecção não é difícil, contudo, a melhor resolução depende da expressão de alguns tecidos e de alterações ontogenéticas provocadas por fatores ambientais, como estresse hídrico, doenças e injúrias (TOMYAMA \& STAHMANN, 1964;
NOVACKY \& HAMPTON, 1968; SANTOS et al. 1997).

Com relação à esterase (EST), seis regiões foram detectadas, cujas variantes quali e quantitativas permitiram a separação de quase todos os genótipos, tal como na peroxidase. A diferença foi que, nesse sistema, os padrões de L 133 e L 140 foram idênticos (Figura 1- EST).

Os padrões obtidos com a EST e a POX foram os únicos que conseguiram separar fenotipicamente a cultivar IAC Tupã dos demais genótipos. Esse resultado é importante porque, por ser uma planta autógama, alguns autores têm encontrado dificuldades para encontrar variantes eletroforéticas, mesmo que fenotípicas, devido ao alto grau de uniformidade genética encontrada entre os materiais estudados. Assim, os resultados desse trabalho sugerem que esses dois sistemas são indicados para detectar variações enzimáticas no amendoim. Contudo, é imprescindível que a população apresente considerável variabilidade, no aspecto agronômico ou no morfológico, para que se elevem as chances de flagrar variantes em nível enzimático. Por outro lado, o tipo e idade do tecido são fatores preponderantes para a obtenção dessas variantes. Grande parte dos trabalhos desenvolvidos com essa cultura é realizado com sementes, contudo SANTOS et al. (1997) têm conseguido detectar marcadores utilizando tecidos de raízes e folíolos novos, antes do início de floração das cultivares.

A análise dos componentes principais com o padrão de bandas dos cinco sistemas enzimáticos indicou que as duas primeiras componentes principais englobaram $75 \%$ da variação total. Por essa razão, elas foram escolhidas para representar as novas variáveis a partir dos dois primeiros autovetores.

A distribuição dos pontos correspondentes a cada genótipo no plano formado pelas primeira e segunda componentes principais consta na Figura 2. Do exame dessa figura, constata-se a presença de quatro grupos de materiais, o primeiro constituído pela linhagem L 146 AM (6), o segundo pelas L 133 AM (3) e L 140 AM (5), o terceiro com a Senegal 55 437 (2), a L 135 AM (4) e a L 197 AM (7) e o quarto representado pela IAC Tupã, único material sensível à seca e que aparece como entidade isolada, numa indicação clara de que ela pôde ser separada, especialmente da cultivar resistente, Senegal 55 437, pela distribuição do conjunto dos padrões de bandas exibidos. Nessas condições, constata-se que a classificação de genótipos baseada nos padrões de isoenzimas,pode se constituir em um método preliminar para separação de materiais com resistência à seca, mesmo sem a imposição deliberada de estresse hídrico às plantas. 


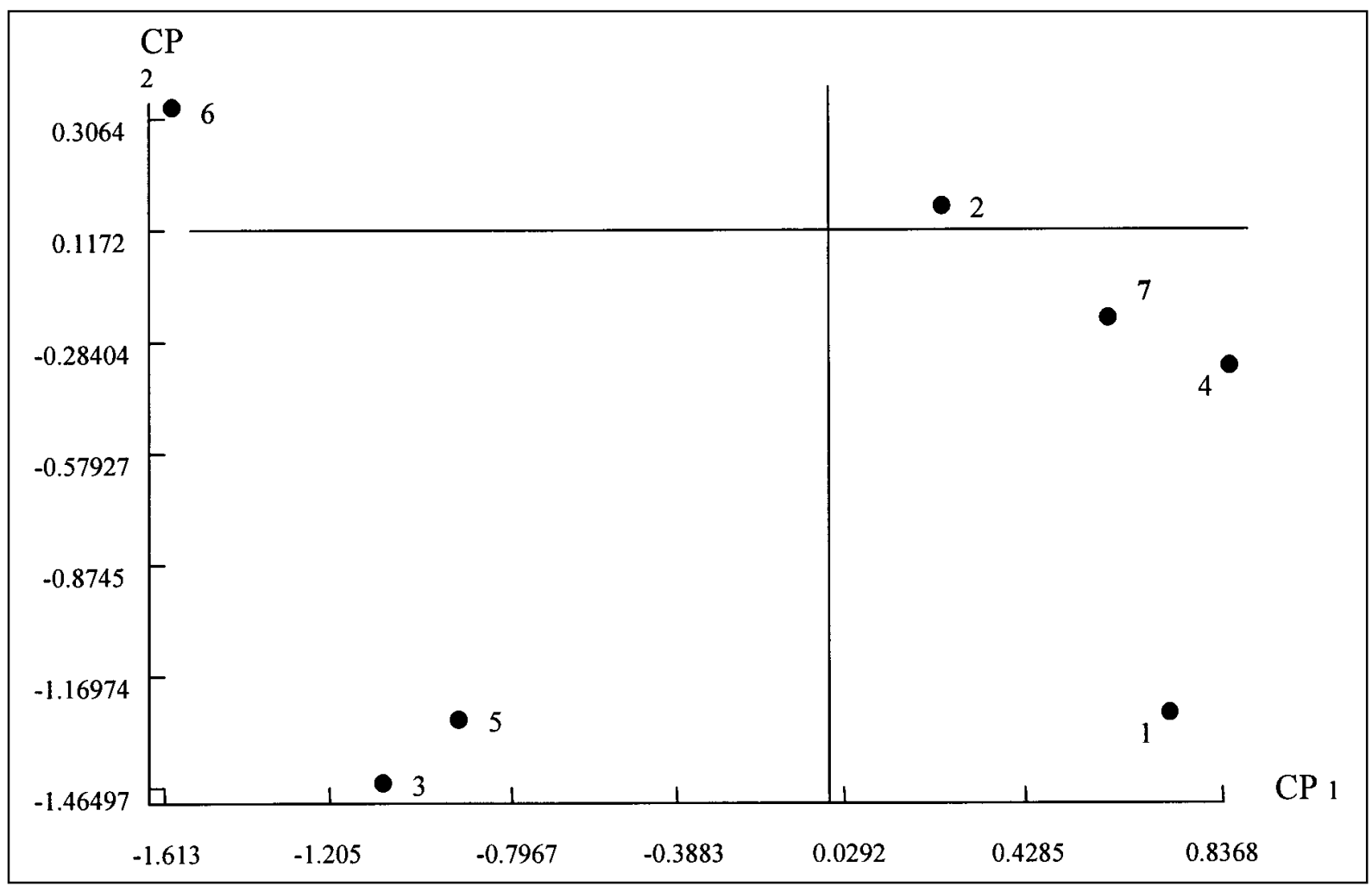

Figura 2 - Distribuição dos pontos correspondentes aos genótipos no plano formado pelas duas primeiras componentes principais (1- IAC Tupã, 2- Senegal 55 437, 3- L 133 AM, 4- L 135 AM, 5- L 140 AM, 6- L 146 AM e 7- L 147 AM ).

\section{CONCLUSÕES}

Os sistemas enzimáticos testados permitiram a classificação dos genótipos em quatro grupos distintos, sendo que o genótipo sensível à seca agrupou separadamente entre os demais. A classificação das linhagens, considerando-se o conjunto de bandas de todas as isoenzimas, possibilitou separar os genótipos, mesmo sem ter de submetê-las ao estresse hídrico deliberado.

\section{REFERÊNCIAS BIBLIOGRÁFICAS}

ALFENAS, A.C., PETERS, I., BRUNE, W., et al. Eletroforese de proteínas e isoenzimas de fungos e essências florestais. Viçosa : UFV, 1991. 242p.

BOOTE, K.J., STANSELL, J.R., SCHUBERT, A.M., et al. Irrigation, water use and water relation. In: PATEE, H.E.; YOUNG, C.T. (Eds). Peanut science and tecnology. Texas : American, 1982. Cap. 7. p.164-205.

CHERRY, J.R., ORY, R. L. Characterization of isoperoxidase activity in Arachis hypogaea cultivars. Phytochemistry, Oxford, v.12, p.1581-1583, 1973.

DUARTE, J.M. Caracterização eletroforética de amendoim (Arachis hypogaea L.) resistente à seca cultivado em condições normais. Paraíba, 1995. 81 p. Monografia (Graduação em Agronomia) - Curso de Agronomia, Universidade Federal da Paraíba, 1995.

GALGARO, M.L., LOPES, C.R. Isoenzimatic variability among five peanuts cultivars. Bragantia, São Paulo, v.53, p.135-140, 1994.

GRIESHAMMER, U., WYNNE, J.C. Isenzyme variability nature seeds of U. S. Peanuts cultivars and collections. Peanut Science, Yoakum, v.8, p.72-75, 1990.

HALL, R. Molecular approaches to taxonomy of fungi. Botanical Review, New York, v.35, p.285-304, 1969.

LONGO, J.P., SCANDALIOS, J.G. Nuclear gene control of the mitochondriae molic deydrogenase in maize. Proceeding of National Academy Science, Washington, v.62, p.104-111, 1963.

MOREIRA, J. de A,N., SANTOS, J.W. dos, OLIVEIRA, S.R. de M. Abordagens e metodologias para avaliação de germoplasma. Brasilia : EMBRAPA/CNPA; EMBRAPASPI, 1994. 115p.

NEWTON, K.J., SCHWARTZ, D. Genetic basis of the major malate daydrogenase isoenzymes in mayse. Genetics, Texas, v.95, p.425-442, 1980.

NOVACKY, A., HAMPTON, R.E. Peroxidase in virus infected plants. Phytopathology, St. Paul, USA, v.50, p.301-305, 1968.

Ciência Rural, v. 30, n. 2, 2000. 
QUIROS, C.F. Identification of alfafa by enzyme eletrophoresis. Crop Science, Madison, v.20, p.262-264, 1980.

SANTOS, R.C. dos. Ivestigação genético-bioquímica de cultivares de feijão (Phaseolus vulgaris L.) resistentes e suscetíveis ao agente da antracnose (Colletotrichum lindemuthianum. Sacc. et Magn Scrib.). Recife, 1989. 120p.

Dissertação (Mestrado em Botânica)- Curso de Pós-graduação em Botânica, Universidade Federal Rural de Pernambuco. 1989.
SANTOS, R.C.dos, MOREIRA, J. de A.N., CABRAL, E.L. Estudo da peroxidase na fenologia do amendoim submetido à estresse hídrico. Oleaginosas e Fibrosas, Campina Grande, v.1, n.1, p.117-124, 1997.

TOMIYAMA, K., STAHMANN, M.A. Alteration oxidase enzyme in potato tuber by infecction with. Phyphtora infestans. Plant Physiology, Maryland, v.39, p.483-490, 1964.

Ciência Rural, v. 30, n. 2, 2000. 